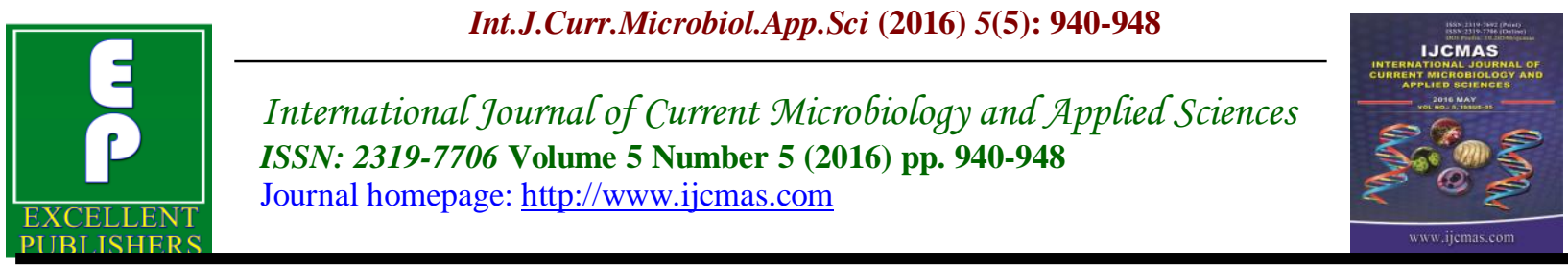

Original Research Article

http://dx.doi.org/10.20546/ijcmas.2016.505.099

\title{
A Comparative study to assess the knowledge of married women regarding contraceptive methods in selected rural and urban community of Raikot, Ludhiana, Punjab, India
}

\author{
Rajwant Kaur Randhawa* \\ PG (Community Health Nursing), Guru Hargobind College of Nursing, \\ Raikot, Ludhiana, Punjab, India \\ *Corresponding author
}

\author{
A B S T R A C T
}

\section{Keywords}

Rural and Urban women, contraceptive methods.

\begin{tabular}{l}
\hline Article Info \\
\hline Accepted: \\
20 April 2016 \\
Available Online: \\
10 May 2016
\end{tabular}

The present study was conducted to assess the knowledge of married women regarding contraceptive methods in selected rural and urban community of Raikot, Ludhiana, and Punjab. The research project was undertaken by Mrs. Rajwantkaur in partial fulfillment of the requirement for the degree of Master of Science in nursing, of Baba Farid University of Health Sciences, Faridkot in 2013. Hence the researcher felt the importance to assess the knowledge of married women regarding contraceptive methods. The objective of the study were to assess the knowledge of rural and urban married women regarding contraceptive methods, to find out the relationship between the knowledge of married women with selected variables such as age, education of the women, occupation of the women, type of family, Duration of marriage, number of children, monthly income of the family, health agency facilities, source of the information. The conceptual framework of the study was based on Orem's self care deficit (1991) theory. A comparative approach was adopted for the study. Non probability convenience sampling was used and 100 samples (rural50 and urban 50) were selected. Demography Performa was used to obtained background information of the women. The structured knowledge questionnaire was used to assess the knowledge on contraceptive methods. Descriptive and inferential statistics was used to analyze the data. Frequency and percentage, chi-square, t test, Anova were used for the analysis. Following results were drawn based on the finding of the study that urban women had better knowledge than the rural women. This study has identified that the comparison of the rural and urban women knowledge statistically significant at $(\mathrm{p}<0.05)$ was found with demographic variables such as age, education of the women, occupation of the women, type of family, Duration of marriage, number of children, monthly income of the family, health agency facilities, source of the information on knowledge regarding contraceptive methods. Maximum mean knowledge score percentage of urban married women was found in the area of introduction and rural women high knowledge score was found in the area of permanent methods and the least in introduction. Pamphlets on contraceptive methods were prepared by investigator to improve knowledge of married women regarding contraceptive methods. Conclusions were drawn based on findings of the study that equal attention is needed on both rural and urban women to improve their existing knowledge of contraceptive methods. Based on the experience gained during the periods of study and from the results of the study, these recommendation were made that the study can be replicated on large sample to validate and generalize its finding; similar study can be conducted in a different setting like two different cities ; An experimental study can be done to assess the effectiveness of hand book on the knowledge among married and unmarried women/men Regarding contraceptive methods in selected area; A cross sectional study can be carried out to assess the knowledge and attitude of eligible couples regarding contraceptive methods. 


\section{Introduction}

Contraception or birth control generally refers to a plan or method used to alter or avoid natural state of fertility, thereby, preventing or reducing the probability of pregnancy without abstaining from sexual intercourse. Contraception aims to prevent pregnancy and this can be achieved by contraceptive methods.

Spacing methods are barrier, physical and chemical methods, hormonal methods, intra-uterine devices, post- conception methods, and miscellaneous or natural methods. Terminal methods, male sterilization and female sterilization, Park (2009).

The aim of the study is to create awareness among women regarding the contraceptive methods. The objectives of this study includes, to assess the knowledge of rural married women regarding contraceptive methods. To assess the knowledge of urban married women regarding contraceptive methods. To compare the knowledge of rural and urban married women regarding contraceptive methods. To find out the relationship between the rural married women regarding contraceptive methods with selected variables such as age, education, religion, Occupation, type of family no of children, income of family, source of information. To find out the relationship between the urban married women regarding contraceptive methods with selected variables such as age, parity, education, occupation, type, of family, duration of marriage, number of children, income of family, health agency facilities and source of information. And also to find out the deficit area and provide pamphlets on contraceptive methods.

\section{Operational Definitions}

Knowledge: It refers to understanding of family planning methods as a result of knowledge on the familiarity gained by experience or learning.

Married women: It refers to women in the age group of 18 to 45 years and living with husband.

Contraceptive method: It includes all the temporary and permanent preventive methods to help women to avoid unwanted pregnancies.

\section{Assumption}

Urban women do have higher level of knowledge than rural women

Educated women do have more knowledge than illiterate women

\section{Conceptual framework}

The conceptual framework of the present study was based on Dorothy Orem's (1991) theory of self care deficit. Orem 's theory of self Care deficit was based on the major concepts that are self care dependent, Self care agency, self care deficits, nursing agency. Therapeutic self care demand and self care requisites.

Literature related to knowledge regarding contraceptive methods.

Philpson, (2011) 23 conducted a study to assess the women's knowledge, belief and information in relation to the risk and benefits associated with use of oral contraceptive pills on 1200 women aged 1850 years. The result of the 305 women who have reported $93 \%$ had used the oral contraceptive at some time in their lives, with $32 \%$ reported current usage. Only 50\% of women were satisfied with previously assessed information. Less than $40 \%$ of the sample reported a high level of confidence 
in their knowledge of the risk, benefit and side effects of oral contraceptive pills used.

Fampract SA (2010) 25 conducted a study among 150 people in which researcher assessed that $56 \%$ of them knew about contraception, $88 \%$ of participants learned about contraceptive methods from health workers/nurses/ doctors/ media/ school and friends. $54 \%$ reported that they use condoms. $12.8 \%$ of young women reported that they conceive when they are not willing to be pregnant. It concludes that there was lack of knowledge regarding the contraception.

\section{Methodology}

A comparative approach was used for the present study it aimed to compare the knowledge of married women regarding contraceptive method. In among rural and urban community Raikot, Ludhiana, Punjab.

\section{Independent Variables}

Independent variables included in the study were age, education of the women, occupation of the women, type of family, Duration of marriage, number of children, monthly income of the family, health agency facilities, source of the information.

\section{Dependent Variable}

Knowledge of married women regarding contraceptive method of rural and urban community

\section{Research Setting}

The study was conducted among married women in selected rural area of Noorpura and urban area of Raikot. The rural area of Noorpura is situated on Ludhiana-Ferozpur high way about $2 \mathrm{kms}$. From GHG of nursing and the Urban area of Raikot is situated on Barnala to Ludhiana state high way about $3 \mathrm{kms}$ from GHG college of nursing. The Rural area is more developed then other nearby areas. The total population of rural village were2900. and population of urban Raikot were 4500. The total population of both groups rural and urban community was 100 from which 50 rural married women and 50 urban married women were selected.

\section{Target Population}

The target population of study consisted of married women of rural areas of Dhaka and urban areas of Mulapur community.

\section{Sample and Sampling Technique}

The total sample size was 100 married women of which 50 married women of Rural and 50 married women of urban was taken by non probability convenience sampling technique.

\section{Development and Description of Tool}

Part 1: It was related to demographic data and not included in the scoring system.

Part 11: Total number of items in this part was 40. Each items had a score of one (1) mark for correct answer and zero (o) for incorrect answer.

\section{Pilot Study}

Pilot study was conducted in the first week of February 2013 to insure the reliability of tool and feasibility of the study after obtaining the formal permission from the concerned Gram Panchayat for Rural area Dakha village and from the Nagar Council for Urban area Mulapur Ludhiana. Table. 2 reveals that overall level of knowledge of 
rural married women was average. Majority of the rural women 34 (68\%) had average knowledge and 15 (30\%) had only good knowledge. Thus, it was evident that most of rural women had average knowledge and very few had good knowledge.

Table. 3 reveals that overall level of knowledge among urban married women. Majority of the urban women $41(82 \%)$ had good knowledge, followed 9 (18\%) had average knowledge.
Thus, it was evident that most of urban women had good knowledge and very few had average knowledge.

Table 4 shows that mean knowledge score of urban women was higher 50 (23.68) than mean knowledge score of rural women 50 (18.76) which was significant at $p<0.05$ and $\mathrm{p}<0.01$ level. Hence, it was concluded that urban married women had higher knowledge as compared to rural women.

Table.2 Percentage Distribution of level of Knowledge of married women regarding contraceptive methods

\begin{tabular}{|c|c|c|c|c|}
\hline & & \multicolumn{3}{|c|}{$\begin{array}{l}\text { Knowledge score } \\
\text { Rural married women }(n=50)\end{array}$} \\
\hline \multicolumn{2}{|c|}{ Level of knowledge (\%) } & Score & $\mathbf{n}$ & $\%$ \\
\hline Excellent & $(>75 \%)$ & $31-40$ & 00 & 0.00 \\
\hline Good & $(50-75 \%)$ & $21-30$ & 15 & 32.00 \\
\hline Average & $(25-50 \%)$ & $11-20$ & 35 & 68.00 \\
\hline \multicolumn{2}{|c|}{ Below average $(<25 \%)$} & $<10$ & 00 & 0.00 \\
\hline
\end{tabular}

$\mathrm{N}=100 ;$ Maximum knowledge score $=40 ;$ Minimum score $=0$

Table.3 Percentage Distribution of level of Knowledge of married women regarding contraceptive methods

\begin{tabular}{|c|c|c|c|c|}
\hline & & \multicolumn{3}{|c|}{$\begin{array}{l}\text { Knowledge score } \\
\text { Urban married women }(n=50)\end{array}$} \\
\hline \multicolumn{2}{|c|}{ Level of knowledge (\%) } & Score & $\mathbf{n}$ & $\%$ \\
\hline Excellent & $(>75 \%)$ & $31-40$ & 00 & 0.00 \\
\hline Good & $(50-75 \%)$ & $21-30$ & 41 & 82.00 \\
\hline Average & $(25-50 \%)$ & $11-20$ & 09 & 18.00 \\
\hline \multicolumn{2}{|c|}{ Below average $(<25 \%)$} & $<10$ & 00 & 0.00 \\
\hline
\end{tabular}


Table.4 To compare the knowledge of rural and urban married women regarding contraceptive methods

\begin{tabular}{llllll}
\hline \multirow{2}{*}{ Married women } & \multicolumn{5}{l}{ Knowledge score } \\
\cline { 2 - 6 } & $\mathbf{n}$ & Mean & SD & df & t \\
\hline Rural & 50 & 18.76 & 4.58 & 98 & $5.23 * *$ \\
Urban & 50 & 23.68 & 3.63 & & \\
\hline \multicolumn{5}{c}{ N=100; Maximum knowledge score $=40 ;$ Minimum score $=0 ; * *$ Significant at $0.01 \%$ level }
\end{tabular}

Table.5 Relationship of Knowledge Score of Rural and Urban married women regarding contraceptive methods according to Age

\begin{tabular}{lllllll}
\hline \multicolumn{7}{c}{ Knowledge score } \\
\hline Age in years & \multicolumn{7}{c}{ Rural (50) } & \multicolumn{1}{c}{ Urban (50) } \\
\cline { 2 - 7 } & n & Mean & SD & n & Mean & SD \\
\hline $18-24$ & 04 & 17.75 & 3.775 & 06 & 23.67 & 2.422 \\
$25-31$ & 07 & 18.86 & 3.237 & 08 & 22.62 & 2.669 \\
$32-38$ & 24 & 18.62 & 4.771 & 24 & 23.26 & 3.633 \\
$39-45$ & 15 & 19.20 & 4.281 & 12 & 24.83 & 4.569 \\
Between group & 03 & & $0.113^{\mathrm{NS}}$ & 03 & $0.714^{\mathrm{NS}}$ \\
Within group & \multicolumn{7}{c}{46} & \\
\hline \multicolumn{7}{c}{ N=100; Maximum knowledge score =40; Minimum score = 0; NS-Non: significant at $\mathrm{p}<0.05$ level }
\end{tabular}

Table.6 Relationship of knowledge score of rural and urban married women regarding contraceptive methods according to Education of women

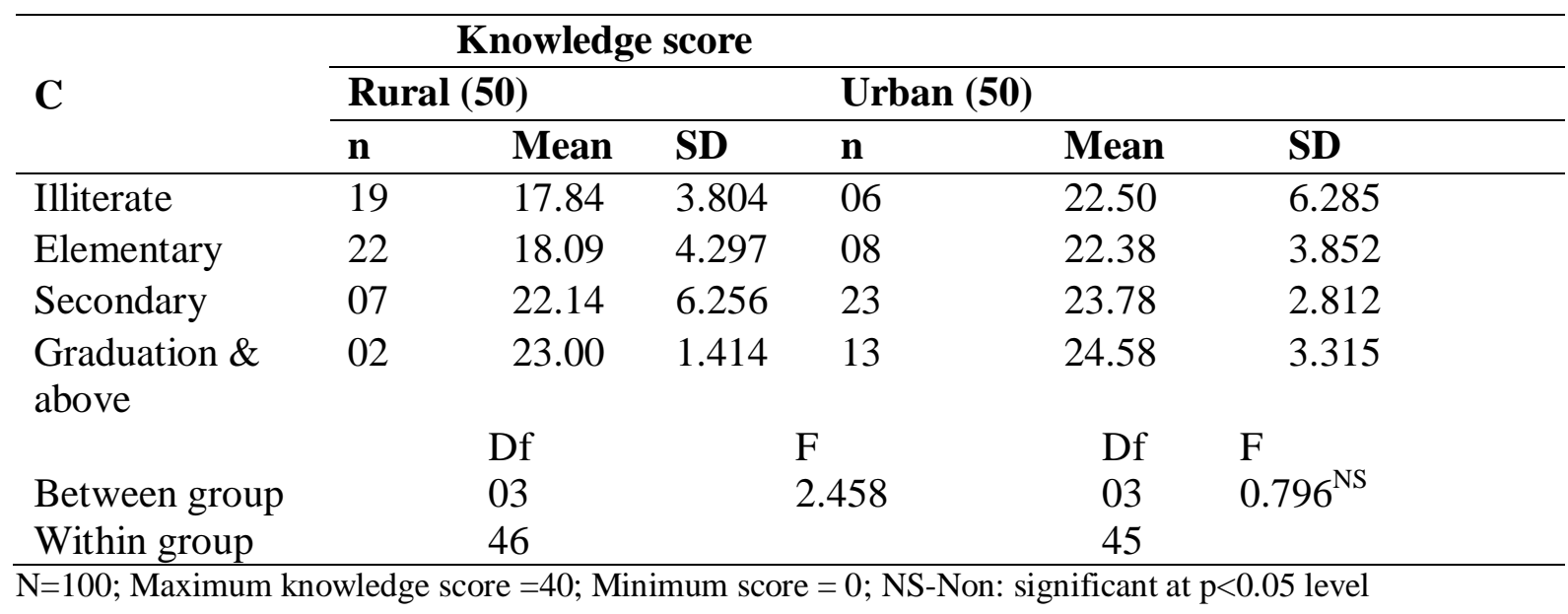


Table.7 Relationship of knowledge score of rural and urban married women regarding contraceptive methods according to religion

\begin{tabular}{|c|c|c|c|c|c|c|}
\hline \multirow{3}{*}{ Religion } & \multicolumn{4}{|c|}{ Knowledge score } & & \multirow[b]{3}{*}{ SD } \\
\hline & \multicolumn{3}{|c|}{ Rural (50) } & \multicolumn{2}{|c|}{ Urban (50) } & \\
\hline & $\mathbf{n}$ & Mean & SD & n & Mean & \\
\hline Hindu & 10 & 17.70 & 3.622 & 34 & 23.65 & 3.692 \\
\hline Sikh & 40 & 19.02 & 4.790 & 16 & 23.47 & 3.563 \\
\hline Muslim & 00 & - & - & 00 & - & - \\
\hline \multirow[t]{2}{*}{ Christian } & 00 & - & - & 00 & - & - \\
\hline & & Df & & t & & \\
\hline Rural & & 48 & & $0.419^{\mathrm{NS}}$ & & \\
\hline Urban & & 48 & & $0.874^{\mathrm{NS}}$ & & \\
\hline
\end{tabular}

$\mathrm{N}=100$; Maximum knowledge score $=40$; Minimum score $=0$; NS-Non: significant at $\mathrm{p}<0.05$ level

Table.8 Relationship of knowledge score of rural and urban married women regarding contraceptive methods according to Occupation of the women

\begin{tabular}{|c|c|c|c|c|c|c|}
\hline \multirow{3}{*}{ Occupation } & \multicolumn{4}{|c|}{ Knowledge score } & & \\
\hline & \multicolumn{3}{|c|}{ Rural (50) } & \multicolumn{2}{|c|}{ Urban (50) } & \multirow[b]{2}{*}{ SD } \\
\hline & $\mathbf{n}$ & Mean & SD & n & Mean & \\
\hline Homemaker & 37 & 18.19 & 4.326 & 15 & 23.00 & 3.703 \\
\hline Labourer & 07 & 17.86 & 5.273 & 24 & 23.58 & 4.010 \\
\hline Service & 04 & 21.75 & 2.062 & 05 & 25.80 & 2.387 \\
\hline \multirow[t]{2}{*}{ Self-employed } & 02 & 26.50 & 0.707 & 06 & 23.20 & 1.789 \\
\hline & & df & & 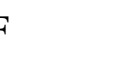 & Df & $\mathrm{F}$ \\
\hline Between group & & 03 & & $.113^{*}$ & 03 & $0.783^{\mathrm{NS}}$ \\
\hline Within group & & 46 & & & 45 & \\
\hline Turkey's HSD & & 1 vs $4 *$ & & & & \\
\hline
\end{tabular}

$\mathrm{N}=100$; Maximum knowledge score $=40$; Minimum score $=0$; NS-Non: significant at $\mathrm{p}<0.05$ level

Table.9 Relationship of knowledge score of rural and urban married women regarding contraceptive methods according to Type of family

\begin{tabular}{|c|c|c|c|c|c|c|}
\hline \multirow{3}{*}{ Occupation } & \multicolumn{4}{|c|}{ Knowledge score } & & \multirow[b]{3}{*}{ SD } \\
\hline & \multicolumn{3}{|c|}{ Rural (50) } & \multicolumn{2}{|c|}{ Urban (50) } & \\
\hline & $\mathbf{n}$ & Mean & SD & $\mathbf{N}$ & Mean & \\
\hline Nuclear & 15 & 19.47 & 5.235 & 36 & 23.77 & 3.750 \\
\hline \multirow[t]{2}{*}{ Joint } & 35 & 18.46 & 4.314 & 14 & 23.14 & 3.348 \\
\hline & \multicolumn{3}{|c|}{ df } & \multicolumn{3}{|c|}{ - } \\
\hline Rural & \multicolumn{3}{|c|}{48} & \multicolumn{3}{|c|}{$0.711^{\mathrm{NS}}$} \\
\hline Urban & \multicolumn{3}{|c|}{48} & \multicolumn{3}{|c|}{$0.546^{\mathrm{NS}}$} \\
\hline
\end{tabular}

$\mathrm{N}=100$; Maximum knowledge score $=40$; Minimum score $=0$; NS-Non: significant at $\mathrm{p}<0.05$ level 
Table.10 Relationship of knowledge score of rural and urban married women regarding contraceptive methods according to Duration of marriage

\begin{tabular}{|c|c|c|c|c|c|c|}
\hline \multirow{3}{*}{$\begin{array}{l}\text { Duration of } \\
\text { marriage }\end{array}$} & \multicolumn{4}{|c|}{ Knowledge score } & & \\
\hline & \multicolumn{3}{|c|}{ Rural (50) } & \multicolumn{2}{|c|}{ Urban (50) } & \multirow[b]{2}{*}{ SD } \\
\hline & $\mathbf{N}$ & Mean & SD & $\mathbf{N}$ & Mean & \\
\hline $1-3$ yrs & 05 & 18.40 & 4.775 & 05 & 24.60 & 0.894 \\
\hline $4-6$ yrs & 09 & 17.67 & 3.742 & 13 & 22.42 & 3.579 \\
\hline $7-10 \mathrm{yrs}$ & 22 & 19.23 & 4.908 & 20 & 23.95 & 3.379 \\
\hline \multirow[t]{2}{*}{$>11 \mathrm{yrs}$} & 14 & 18.86 & 4.818 & 12 & 23.75 & 4.693 \\
\hline & & Df & & $\mathrm{F}$ & Df & $\mathrm{F}$ \\
\hline Between group & & 03 & & $0.248^{\mathrm{NS}}$ & 03 & $0.610^{\mathrm{NS}}$ \\
\hline Within group & & 46 & & & 45 & \\
\hline
\end{tabular}

$\mathrm{N}=100$; Maximum knowledge score $=40$; Minimum score $=0$; NS-Non: significant at $\mathrm{p}<0.05$ level

Table.11 Relationship of knowledge score of rural and urban married women regarding contraceptive methods according to Number of children

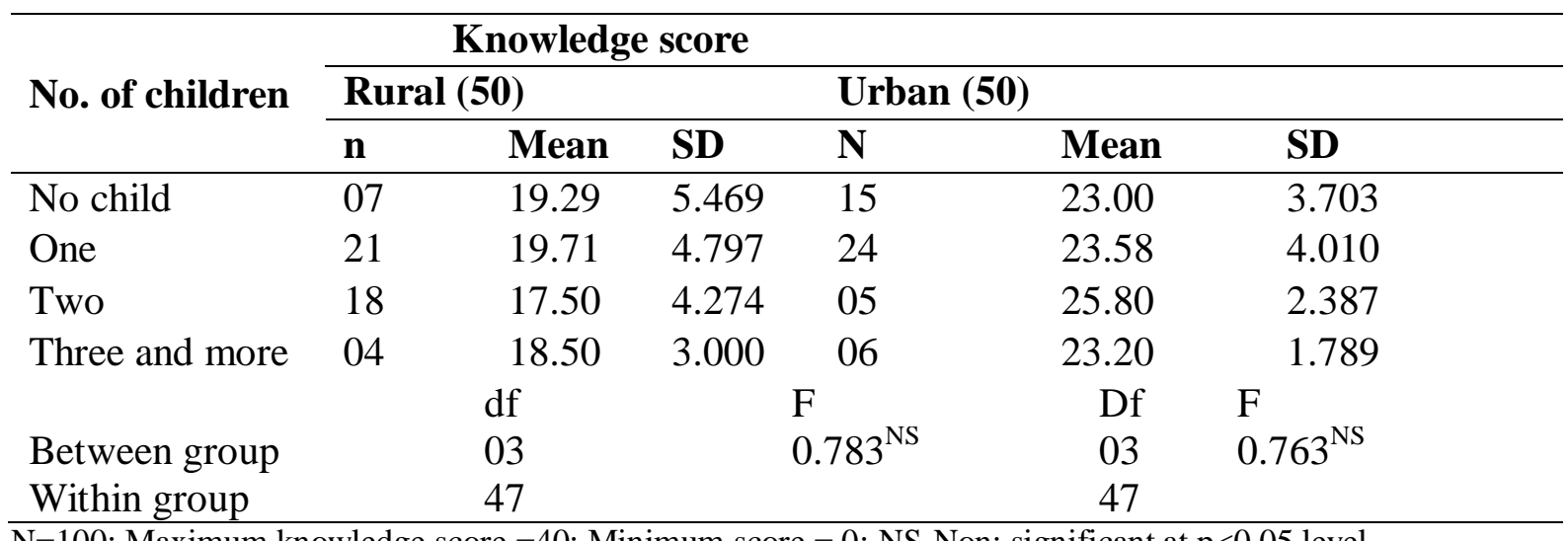

$\mathrm{N}=100$; Maximum knowledge score $=40$; Minimum score $=0$; NS-Non: significant at $\mathrm{p}<0.05$ level

Table.12 Relationship of knowledge score of rural and urban married women regarding contraceptive methods according to monthly income of the family

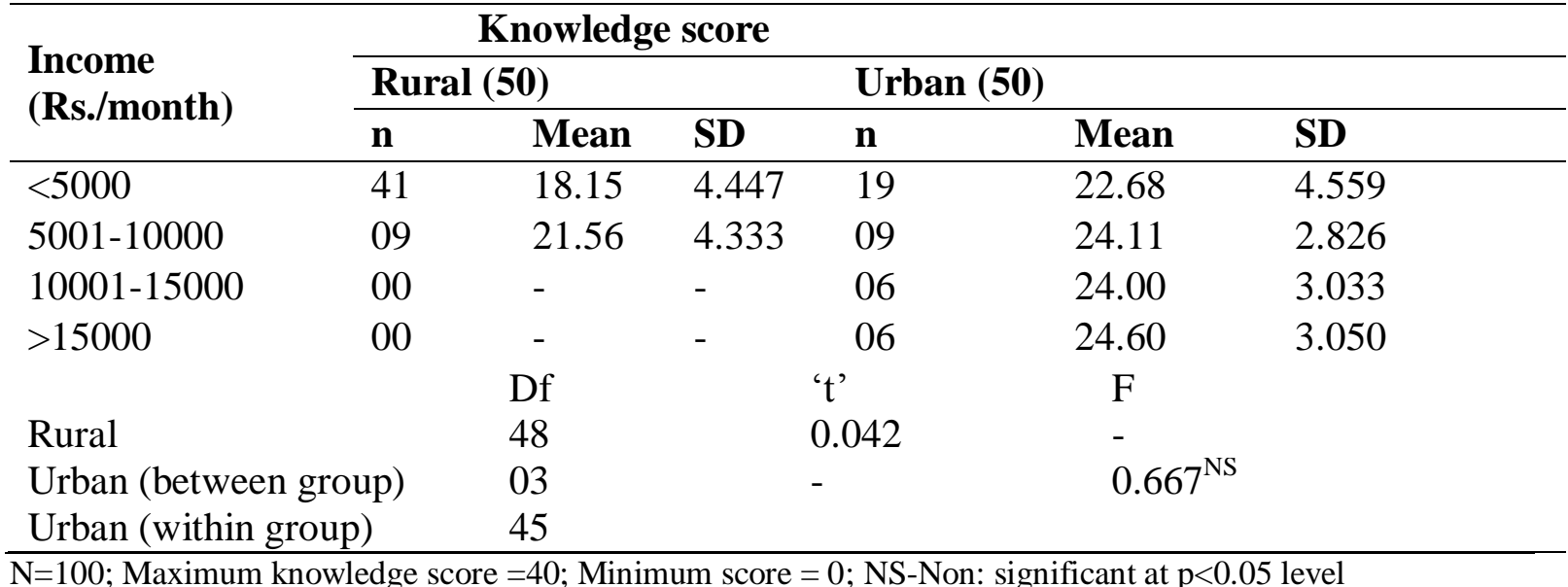


Table.13 Relationship of knowledge score of rural and urban married women regarding contraceptive methods according to Health agency facilities

\begin{tabular}{|c|c|c|c|c|c|c|}
\hline \multirow{3}{*}{$\begin{array}{l}\text { Health agency } \\
\text { facilities }\end{array}$} & \multicolumn{4}{|c|}{ Knowledge score } & & \multirow[b]{3}{*}{ SD } \\
\hline & \multicolumn{3}{|c|}{ Rural (50) } & \multicolumn{2}{|c|}{ Urban (50) } & \\
\hline & $\mathbf{n}$ & Mean & SD & n & Mean & \\
\hline $\mathrm{CHC}$ & 12 & 17.75 & 5.011 & 11 & 23.10 & 3.213 \\
\hline $\mathrm{PHC}$ & 17 & 18.65 & 3.639 & 13 & 23.08 & 5.251 \\
\hline $\mathrm{SC}$ & 12 & 18.33 & 5.193 & 07 & 23.14 & 2.340 \\
\hline \multirow[t]{2}{*}{ Private Hospital } & 09 & 20.89 & 4.833 & 19 & 24.37 & 2.910 \\
\hline & & Df & & $\mathrm{F}$ & Df & $\mathrm{F}$ \\
\hline Between group & & 03 & & $0.875^{\mathrm{NS}}$ & 03 & $0.461^{\mathrm{NS}}$ \\
\hline Within group & & 47 & & & 47 & \\
\hline
\end{tabular}

$\mathrm{N}=100$; Maximum knowledge score $=40 ;$ Minimum score $=0$; NS-Non: significant at $\mathrm{p}<0.05$ level

Table 5 Hence, it was concluded that age had no impact on the knowledge of rural and urban women regarding contraceptive methods. Table. 6 the relationship between the knowledge score of rural and urban women according to education was found statistically non significant at $\mathrm{p}<0.05 \%$ level Hence it was concluded that education had no impact on the knowledge of rural and urban women regarding contraceptive methods.

Table.7 showed relationship between knowledge score of rural and urban women according to religion was found statistically non significant at $\mathrm{p}<0.05 \%$ level.

Hence it was concluded that religion had no impact on the knowledge of rural and urban women regarding contraceptive methods.

Table 8 Hence, it was concluded that occupation had impact on the knowledge of rural women but not on urban women's knowledge score.

Table 9 Hence it was concluded that type of family had no impact on the knowledge of rural and urban women regarding contraceptive methods.
Table 10 The relationship between the knowledge score of rural and urban married women according to duration of marriage was found statistically non significant at $\mathrm{p}<0.05$ level.

Hence it was concluded that duration of marriage had no impact on the knowledge of rural and urban women regarding contraceptive methods.

Table 11The relationship between the knowledge score of rural and urban married women according to no. of children was found statistically non significant at $\mathrm{p}<0.05$ level.

Hence it was concluded that no. of children had no impact on the knowledge of rural and urban women regarding contraceptive methods. Table 13 and Fig. 14 The relationship between the knowledge score of rural and urban married women according to health agency was found statistically non significant at $\mathrm{p}<0.05$ level. Hence it was concluded that health agency had no impact on the knowledge of rural and urban women regarding contraceptive methods.

In conclusion, most of the married women in 
rural area $(68 \%)$ had only average level of knowledge whereas majority of the married women in urban area (82\%) had good knowledge regarding contraceptive methods of the mean knowledge score regarding contraceptive methods was comparatively higher in urban women $(23.68 \%)$ than in rural women( $18.76 \%)$.

\section{References}

Andrej K. Husband-Wife Agreement, Power Relation And Contraceptive Use. International Family Planning Perspective. (2008) 34:127-137.

Aruna Nigam, Neha Maheshwari, and Anupam Prakash Knowledge of Emergency Contraception and Contraceptive Practices Indian J Community Med. 2010 July; 35(3): 449- 450.

BasvanthappaBT Community Health Nursing $3^{\text {rd }}$ edition 2007 new Delhi 317-324.

Census of States and Union Territories by population:2001 and 2011(Census of India 2011)

CLend (2006) http://www huffing ton post. Com / 2013/03/11/womencontraception-need 2854947.html.

Dutta.D.C.Textbook of Obstetrics including perinatology and contraception. $6^{\text {th }}$ Edition. Calcutta: New Central Book Agency; 2004.

Gilliam M.L.Warden MM Tabia B young lahnas recall contraceptive use (2006) Finer LB Henshow st. Perfect Sex Report Health. 2006 june.

Gurung N.S,Gupta S.K, Hays B.Knowledge of Family Planning and Emergency Contraception in a Rural Female Population .J GMC Nepal. vol2-issue3-

IIPS. East West center program on population, eight million women have unmet need for Family planning in Uttarpradesh: Nate Family Health Survey. Bull 1995 Sep; (1): 1-4.93

Jill L. Schwartz and Henry L (2002) www.ncbi.nhm.nih.gov

Park K. Textbook of preventive and social medicine. $20^{\text {th }}$ Edition. Jabalpur: M/S.th Banarsidas Bhanot; 2009.

Philpsonsr, S. Marrilucita, Sphilpson (2011) Online. Liebertpuv. Com /Doi /Abs 101089/Wh2010 2455

Tripathi V, Nandan D, Salhan S. Determinacy of early discontinuation of IUCD use in rural northern districts of India-a multi-variate analysis. Journal of Biosocial Science 2005; (3): 319- 332.

\section{How to cite this article:}

Rajwant Kaur Randhawa. 2016. A Comparative study to assess the knowledge of married women regarding contraceptive methods in selected rural and urban community of Raikot, Ludhiana, Punjab, India. Int.J.Curr.Microbiol.App.Sci.5(5): 940-948.

doi: http://dx.doi.org/10.20546/ijcmas.2016.505.099 